\title{
Case Report on Horner's syndrome following Thyroidectomy
}

\author{
Syeda Sidra Gillani, Ahmad Zeeshan Jamil
}

Pak J Ophthalmol 2019, Vol. 35, No. 1

See end of article for authors affiliations

Correspondence to:

Syeda Sidra Gillani

Optometrist

M. Phil, FIACLE

DHQ teaching Hospital Sahiwal/

Sahiwal Medical College (SMC)

Email: shahnoor2020@gmail.com
We report a case of 37-year-old Pakistani Punjabi woman who visited the Eye department of DHQ teaching hospital Sahiwal with complaint of drooping of right upper eyelid following the thyroidectomy. This is to highlight the importance of proximity of Thyroid gland and sympathetic trunk. Hence, to make surgeon more vigilant to avoid risk of injury to sympathetic trunk so that potentially stressing cosmetic disfigurement can be avoided. Moreover, this would help the surgeon to undertake measures to lessen the risk of injuring the sympathetic runk while doing the thyroidectomy.

Key words: Horner's syndrome, miosis, ptosisthyroidectomy.
$\mathrm{M}$ iosis and ptosis are the two commonest features of Horner's syndrome. Moreover, it may or may not be associated with ipsilateral facial anhydrosis and dilatation of vessels. It is probably the outcome of traumatized ipsilateral cervical sympathetic chain. Up to now a thorough knowledge of the cause and pathophysiology is not unknown. Once it is diagnosed, the management is conservative. Horner's syndrome is reported to be rarest complication subsequent to thyroidectomy and a few cases are reported worldwide. We would like to report such a case in Pakistan where thyroid disorders are abundant and thyroidectomy is a common surgical procedure $^{1,2}$.

\section{CASE HISTORY}

A 37-year-old Pakistani Punjabi woman visited eye department of DHQ teaching hospital Sahiwal with complaint of drooping of Right upper eyelid. After taking complete history it became evident that patient had developed unilateral partial ptosis as well as miotic pupil following the thyroidectomy which is done for a benign multinodular goiter. There was no history of facial anhidrosis reported by the patient.

On examination it was found there was mild

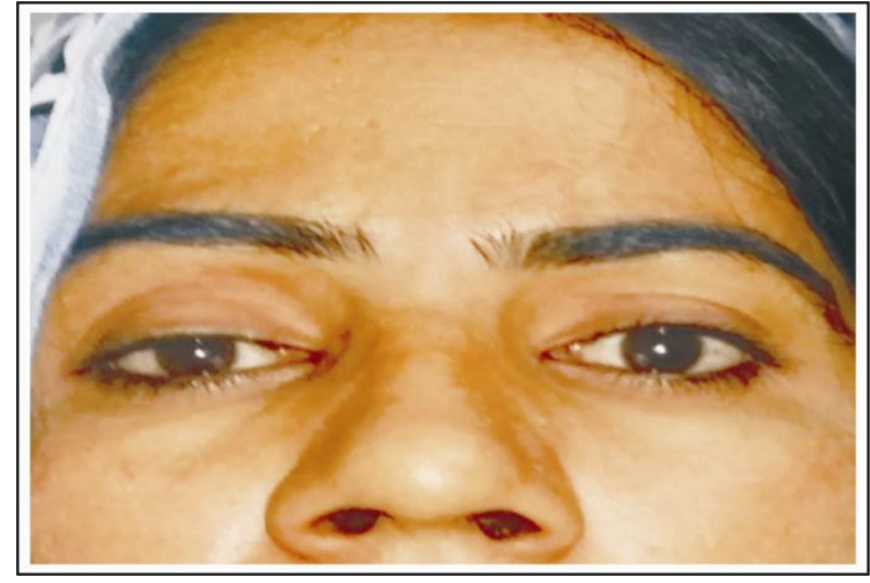

Fig. A: Photographs of patient showing right ptosis and surgical mark of thyroidectomy.

ptosis in right eye with miosis. Marginal reflex distance was found to be $2 \mathrm{~mm}$ in right eye and $4 \mathrm{~mm}$ in left eye. Palpebral fissure height was measured to be $6 \mathrm{~mm}$ in right eye which was $3 \mathrm{~mm}$ less than palpebral fissure height of left eye and normal lid position and retraction. There was no history of anhydrosis, normal sensation and full extra ocular motility in all cardinal position of gaze. Moreover, 
both eyes were centrally placed in the orbit and no dystropia was noted.

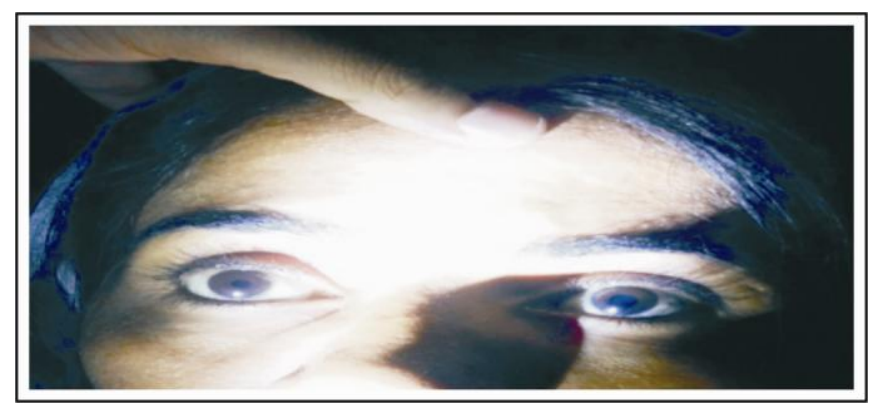

Fig. B: Photographs of patient showing right miosis while patient is looking in up gaze.

A clinical diagnosis of Horner's syndrome was made with phenylephrine $1 \%$ which was prepared by diluting $10 \%$ phenylephrine and instilled in both eye. It produced dilatation in a Horner's syndrome and minimal dilatation in normal pupil because of denervation hyper-sensitivity. Therefore it became clear that lesion was interrupting the postganglionic fibers.

\section{DISCUSSION}

Horner's Syndrome usually presents with miosis, eyelid ptosis, enophthalmos and vascular dilatation disorder. Besides, Facial anhidrosis may or may not be present. In 1853, it was firstly described by Bernard, and after that Johann Horner reported it in 18694. In spite of the fact that there is huge literature which describes Horner's Syndrome is result of pressure caused by majority of benign goiter to cervical sympathetic chain but there may be less than 30 cases of the reported Horner's Syndrome after thyroidectomy so far.

At the very first in 1865, Kappeler explained that Horner's Syndrome might occur after thyroid surgery. A first case of Horner's Syndrome post thyroidectomy was reported by the Kaelin in early 1900's ${ }^{5}$. Horner's Syndrome with conventional surgical procedure of thyroidectomy is quite possible and however the late reports propose that comparative dangers of harm to sympathetic innervation are related with minimal invasive surgery also. Then, Harding et al. has lately described the Horner's Syndrome following minimal invasive parathyroidectomy, on the other side Meng with his partners have revealed Horner's Syndrome following video assisted surgery6.
A possible explanation behind Horner's Syndrome following thyroid surgery are, the sympathetic chain may get stretched during Lateral retraction or compressed by a hematoma post operatively, ligation of inferior arterial trunk of thyroid can cause ischemia induced damage to neural tissue. Besides, communication between sympathetic innervation and laryngeal nerve may get affected due to its repetitive identification during procedure. Anatomically, the middle cervical ganglion and sympathetic truck are very close and relation is quite variable either present in front or behind the inferior thyroid artery. That's why middle cervical ganglion and sympathetic truck are profoundly prone to complications in thyroidectomy. Solomon et al. proposed that blood supply to the sympathetic trunk originated from the inferior thyroid trunk or its branches and ligation of these vessels may cause prompt devascularization and ischemic damage to the sympathetic chain prompting Horner's Syndrome ${ }^{7}$.

De Quervain says that sympathetic chain gets stretched when the lateral retraction of carotid sheath is done to expose the lateral aspects of gland and other close structures. This stretching is sufficient to cause damage to the chain and subsequently neuropraxictype trauma occurs ${ }^{8}$. In a recently published case series by Harding et al. reports that the more complicated surgery higher would be the risk of Horner's Syndrome. For instance in malignant thyroid disease which involves level III lymph node dissection and large goiters with retrosternal extension chances of Horner's Syndrome are relatively higher6.

It is observed that there is no uniform pattern for onset of Horner's Syndrome subsequently thyroidectomy. Most of the literature confirms that Horner's Syndrome starts at $2^{\text {nd }}$ to $4^{\text {th }}$ postoperative day which reflects the possibility of various etiologies. But here in this case we are unable to describe the exact onset of symptoms due to vague medical history given by the patient and lack of medical record.

Patient here did not show any ipsilateral inability of facial sweating and cutaneous vascular dilatation as noted in most of such cases. The exact reason behind is not known so far.

\section{CONCLUSIONS}

This case report features an uncommon however particularly important complication of very common surgery done by general and endocrine and otorhinolaryngology specialists. In spite of the fact 
that it is a rare complication but the specialist should be careful during the procedure because it can cause a noteworthy cosmetic problem, which could last long.

\section{Author's Affiliation}

Syeda Sidra Gillani

BSc(hons)Optometry/M.phil Optometry

Optometrist

DHQ teaching Hospital Sahiwal

Dr. Ahmad Zeeshan Jamil

Associate Professor of Ophthalmology

MBBS, MCPS, FCPS, FRCS, FCPS (VRO)

Sahiwal medical college/DHQ teaching Hospital

Sahiwal

\section{Author's Contribution}

Syeda Sidra Gillani

Concept of study, drafting of manuscript.

Dr. Ahmad Zeeshan Jamil

Critical review and literature search.

\section{REFERENCES}

1. Seneviratne SA, Kumara DS, Drahaman AMP. Horner's syndrome: an unusual complication of thyroidectomy: a case report. Journal of Medical Case Reports, 2016; 10 (1): 300.

2. Cozzaglio L, Coladonato $M$, Doci $R$, Travaglini $\mathbf{P}$, Vizzotto L, Osio M, et al. Horner's syndrome as a complication of thyroidectomy: report of a case. Surgery today, 2008; 38 (12): 1114-6.

3. Danesh-Meyer HV, Savino P, Sergott R. The correlation of phenylephrine $1 \%$ with hydroxyamphetamine 1\% in Horner's syndrome. British Journal of Ophthalmology, 2004; 88 (4): 592-3.

4. Horner JF. Übereine Form von Ptosis. KlinMonatsbl Augenheilkd. 1869: 7.

5. Kaelin W. Über Störungen von seiten des Halssympathicus bei einfacher Struma und im Anschluß an deren operative Behandlung. Langenbecks Arch Surg. 1915: 134.

6. Harding JL, Sywak MS, Sidhu S, Delbridge LW. Horner's syndrome in association with thyroid and parathyroid disease. ANZ J Surg. 2004: 74.

7. Solomon $\mathbf{P}$, Irish J, Gullane $\mathbf{P}$. Horner's syndrome following a thyroidectomy. J Otolaryngol. 1993; 22 (6): 454-6.

8. Quervain F. Weiteres zur technik der kropfoperation. Langenbecks Arch Surg. 1915: 134. 